Available online at

www.macvetrev.mk

Original Scientific Article

\title{
DETECTION OF RECESSIVE MUTATIONS (BLAD AND CVM) IN HOLSTEIN-FRIESIAN CATTLE POPULATION IN REPUBLIC OF MACEDONIA
}

\author{
Nikola Adamov ${ }^{1}$, Dine Mitrov ${ }^{1}$, Igor Esmerov ${ }^{1}$, Peter Dovc ${ }^{2}$ \\ ${ }^{1}$ Faculty of veterinary medicine, Ss. Cyril and Methodius University \\ in Skopje, Macedonia \\ ${ }^{2}$ Biotechnical faculty, University of Ljubljana, Slovenia
}

Received 2 June 2013; Received in revised form 17 October 2013; Accepted 1 November 2013

\begin{abstract}
BLAD and CVM are Holstein-specific recessive mutations which have had significant economic impact on dairy cattle breeding worldwide. The aim of this study was to optimize a diagnostic test for detection of these two disorders and to obtain a preliminary picture about theire existence in Macedonian HF population. Blood samples were obtained from 84 HF cows from several different farms in Macedonia. Genomic DNA was extracted using DNeasy blood and tissue kit (Qiagen) which was also used for DNA extraction from deeply frozen sperm doses from 6 different HF bulls. Genotyping was performed by PCR-RFLP analysis with TaqI and HaeIII restriction endonucleases for BLAD and with Pst for CVM. The correctness of the genotyping was evaluated by direct sequencing of the amplified products. Among $90 \mathrm{HF}$ cattle tested two cows were identified as carriers of the BLAD allele and one was carrier of the CVM allele. No bulls were found to be carriers of either of the two disorders. This study demonstrates that carriers of BLAD and CVM are present in Macedonia, although at low frequency. PCR followed by RFLP is efficient and inexpensive method for detection of the carriers and should be used as laboratory test in eradication programs. In order to establish a more accurate picture of the prevalence of these disorders, it is necessary to screen a larger number of animals. It is indispensable to test each bull before entering the A.I. program to prevent accidental transmission to a large number of offspring.
\end{abstract}

Key words: BLAD, CVM, bovine autosomal recessive mutations

\section{INTRODUCTION}

Bovine Leukocyte Adhesion Deficiency (BLAD) and Complex Vertebral Malformation (CVM) are recessively inherited diseases in Holstein cattle. They are both lethal in homozygous state while the heterozygous carriers show no clinical signs. When a bull intended for A.I. is a carrier of one or both of these recessive alleles, they can be transmited to a large number of its offspring.

BLAD is inherited granulocytopathy sindrome that is caused by deficiency of the $\beta 2(\mathrm{CD} 11 / \mathrm{CD} 18)$

\footnotetext{
Corresponding author: Nikola Adamov, MSc, DVM

E-mail address: adamovn@fvm.ukim.edu.mk;

Present address: Department of Animal Breeding and Genetics

Faculty of Veterinary Medicine - Skopje

Ss. Cyril and Methodius University in Skopje

Lazar Pop Trajkov 5-7, 1000 Skopje, Republic of Macedonia
}

tel: +38923240770 / fax: +38923114619

Copyright: $\odot 2013$ Adamov N. This is an open-access article published under the terms of the Creative Commons Attribution License which permits unrestricted use, distribution, and reproduction in any medium, provided the original author and source are credited.

Competing Interests: The authors have declared that no competing

interests exist.

Available Online First: 15 November 2013

http://dx.doi.org/10.14432/j.macvetrev.2013.11.005 integrin receptor family expressed on leukocyte cell surface (20). These receptors have identical $\beta$ (CD18) subunit but different $\alpha$ (CD11) subunit and have critical role for extravasation of the neutrofils and migration to the infected tissues. In 1992 Shuster et al. (40) reported that this disorder is caused by a point mutation $(\mathrm{A} 383 \mathrm{G})$ of the bovine $\mathrm{CD} 18$ gene on BTA1 that encodes the $\beta$ (CD18) subunit of the $\beta 2$ integrin receptor family which causes $\mathrm{D}$ to $\mathrm{G}$ amino acid substitution at position 128 of the CD18 subunit $(13,18,37)$. In healthy animals they are normaly expressed on the polymorphonuclear neutrofils cell surface. Affected animals usualy die during their first year of age sice the absence of these receptors results in severe malfunction of the immune system or more precisely in inability of this cells to attach to the blood vessel endothelium and to migrate to the infected tissues. There are numerous published results that have identified this disorder in the Holstein cattle in different countries 
such as in Germany (42), Denmark $(29,3)$, the Nederlands (8), Austria (38), the United Kingdom (6), Japan (27), Switserland (25), France (15), Taiwan (16, 17), Poland (28), Brasil (35), Korea (22), Iran (12), Turkey $(4,5,24)$ and India $(32,33)$. It is internationaly accepted to mark the pedigrees of the carrier animals with the code "BL" and those that are tested free with the code "TL".

CVM is autosomal recessive inherited disorder in the Holstein breed which causes intra-uterine mortality leading to repeat breeding and culling of cows. It has been initially described in the Danish Holstein population in 1999 and shortly thereafter its presence was reported in the United States (11), the United Kingdom (34), the Netherlands (46), and in Japan (26). In 2006 Thomsen et al. (44) identified the molecular basis of this disorder and provided evidence that the missense mutation from $\mathrm{G}$ to $\mathrm{T}$ at nucleotide position 559 of the bovine solute carrier family 35 member 3 (SLC35A3) gene on BTA3 is responsible for this condition. This mutation results in V180F amino acid substitution of the Golgi-resident UDP-N-acetylglucoseamine transporter enzyme which causes abnormal somitogenesis and impaired development of the fetal axial skeleton. The mutation in homozygous recessive state usually leads to death in utero although sometimes alive calves can be born with severe malformations such as hemivertebrae, misshaped vertebrae, ankylosis of mainly the cervico-thoracic vertebrae (fusion of $6^{\text {th }}$ and $7^{\text {th }}$ cervical vertebrae and distortion of the first three thoracic vertebrae), scoliosis, and symmetric arthrogryposis of the lower limb joints $(1,2,30)$. In about $50 \%$ of the affected calves cardiac anomalities such as interventricular septal defects, right displacement of the aorta and hypertrophy of the right heart are observed. It is international standard to mark the pedigrees of the carrier animals with the code "CV" and those that are tested free with the code "TV".

The genealogical analysis of the pedigrees of the affected calves allowed tracing the origin of the both disease-causing alleles back to common ancestors, an elite Holstein bulls Carlin-M Ivanhoe Bell (USA1667366 born in 1974) and his father Pennstate Ivanhoe Star (USA1441440 born in 1963) who have been used for A.I. in many countries throughout the world. Several molecular methods, including PCR-RFLP (9, 39, 41, 43), PCR-PIRA (19), AS-PCR (7, 14), CRS-PCR (45) and SSCP $(10,36)$ have been developed and proved useful for identification of BLAD or CVM carriers in practice. More recently Zhang et al. (47) developed real-time PCR-based assay for discrimination of wild-type 62 and defective alleles which could be more useful for high-throughput sample testing.

The purpose of this study was to optimize and implement a reliable and cost-effective laboratory test for detection of these recessive alleles, as well as to obtain a preliminary results about their existence in the Macedonian HF population.

\section{MATERIALS AND METHODS}

Blood samples were obtained from 84 cattle of the HF breed raised on several different farms in Macedonia. Genomic DNA was extracted using DNeasy blood and tissue kit (Qiagen). This kit was also used for extraction of DNA from deeply frozen sperm doses from 6 different HF bulls that are used in Macedonia for A.I. Before extraction sperm samples $(100 \mu \mathrm{l})$ were lysed with 2xSDS-Lysis buffer and incubated at $56{ }^{\circ} \mathrm{C}$ for 3-4 hours. The target sequences harboring the recessive mutations were amplified by PCR.

For BLAD allele amplification we used primers published previously (21) with the forward primer slightly modified since after checking the sequence for the bovine CD18 gene (GenBank Accession Number Y12672) we noticed that this primer lacks one $\mathrm{C}$ nucleotide. The amplifications were carried out in $25 \mu \mathrm{l}$ reactions containing $1 \times \mathrm{xPCR}$ buffer (Biotools), $200 \mu \mathrm{M}$ dNTP, $2.0 \mathrm{mM} \mathrm{MgCl}, 0.6 \mathrm{U}$ DNA Polymerase (Biotools), $0.2 \mu \mathrm{M}$ of BLAD-F and the same concentration of BLAD-R and 50-100 ng genomic DNA under following conditions: $95^{\circ} \mathrm{C} / 3 \mathrm{~min}$., 35 cycles of $94^{\circ} \mathrm{C} / 1 \mathrm{~min}, 58^{\circ} \mathrm{C} / 1 \mathrm{~min}$, $72^{\circ} \mathrm{C} / 1 \mathrm{~min}$ and final elongation $72^{\circ} \mathrm{C} / 5 \mathrm{~min}$. Amplified products were checked on $2 \%$ agarose gel. Identification of BLAD carriers was performed by digestion of the amplified products with TaqI and HaeIII restriction endonucleases and visualized on $2 \%$ agarose gel for TaqI or 3.5\% agarose gel for HaeIII digestion.

For CVM genotyping we used primers previously published by Kanae et al. (19) in total volume of $25 \mathrm{ul}$ reactions containing 1xPCR buffer (Biotools), $200 \mu \mathrm{M}$ dNTP, $2.0 \mathrm{mM} \mathrm{MgCl}_{2}, 0.6 \mathrm{U}$ DNA Polymerase (Biotools), $0.2 \mu \mathrm{M}$ of CVM-PIRA-F and the same concentration of CVM-PIRA-R and 50-100 ng genomic DNA under following conditions: $94^{\circ} \mathrm{C} / 5 \mathrm{~min}$., 35 cycles of $94^{\circ} \mathrm{C} / 1 \mathrm{~min}, 54^{\circ} \mathrm{C} / 1 \mathrm{~min}$, $72^{\circ} \mathrm{C} / 35 \mathrm{sec}$. and final elongation $72^{\circ} \mathrm{C} / 7 \mathrm{~min}$. Identification of the CVM genotypes was performed by digestion of the amplified product with Pst $\mathrm{I}$ endonuclease. The correctness of the genotyping for both disorders was evaluated by direct sequencing on ABI Prism 310 Genetic Analyzer (Applied Biosystems). 
Recessive mutations of BLAD and CVM in Holstein-friesian cattle in Macedonia

Table 1. Primer sequences, position in the reference sequence and the expected product sizes

\begin{tabular}{|l|l|c|c|}
\hline $\begin{array}{l}\text { Genetic } \\
\text { defect }\end{array}$ & Primer sequence 5'to 3' & Position* & $\begin{array}{c}\text { Expected } \\
\text { product size* }\end{array}$ \\
\hline \multirow{3}{*}{ BLAD } & BLAD-F: CCTGCATCATATCCACCAG & $1007-1025$ & \multirow{2}{*}{$341 \mathrm{bp}$} \\
\cline { 2 - 4 } & BLAD-R: GTTTCAGGGGAAGATGGAG & $1329-1347$ & \\
\hline \multirow{3}{*}{ CVM } & CVM-PIRA-F: CACAATTTGTAGGTCTCACTGCA & $9848-9870$ & \multirow{2}{*}{$287 \mathrm{bp}$} \\
\cline { 2 - 4 } & CVM-PIRA-R: CGATGAAAAAGGAACCAAAAGGG & $10112-10134$ & \\
\cline { 2 - 4 } & SLC-F: GGTCTAAGAGTGGGCTCTAAAC & $9722-9743$ & \multirow{2}{*}{$231 \mathrm{bp}$} \\
\cline { 2 - 4 } & SLC-R: TCCACACTGATTGTTTGGTTTC & $9931-9952$ & \\
\hline
\end{tabular}

* Annealing positions and expected product sizes were determined on basis of previously reported sequences of the CD18 gene for BLAD (GenBank Accession Number Y12672) and SLC35A3 gene for CVM (GenBank Accession Number AY160683)

For BLAD sequencing we used the same forward primer from the PCR-RFLP analysis, while for CVM sequencing we used either SLC-F or SLC-R that we designed with the Primer Premier software. All primers, annealing positions as well as the expected fragment sizes are listed in Table 1.

\section{RESULTS}

The results from the PCR - RFLP analysis for the detection of the BLAD allele carriers are shown in
Fig. 1 and Fig. 2. Digestion of the amplified product of $341 \mathrm{bp}$ with TaqI yielded three fragments of 341 , 191 and 150 bp when carrier DNA was cleaved and two fragments of 191 and $150 \mathrm{bp}$ when non-carrier DNA was cleaved (Fig. 1). Digestion of carrier DNA with HaeIII resulted in six fragments of which the 83 bp one (arrow) was specific for this genotype (Fig. 2).

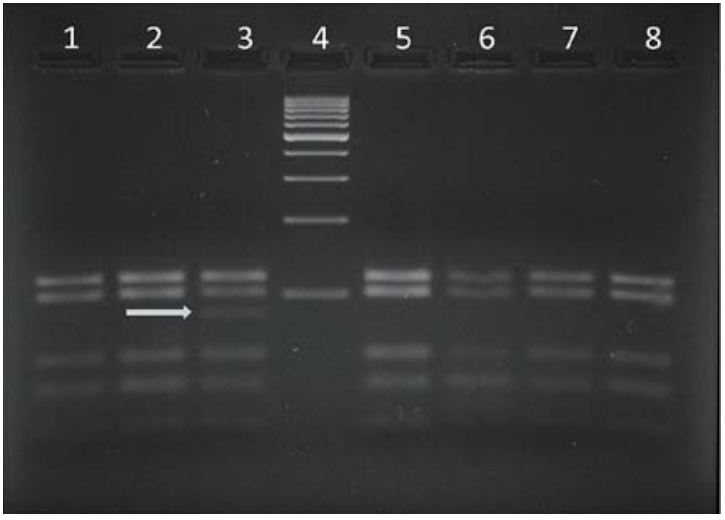

Figure 2. Lanes 1, 2, 5, 6, 7, 8 - BLAD free; lane 3 BLAD carrier; lane 4 - GeneRuler 100 bp DNA Ladder (Thermo Scientific)
Figure 1. Lanes $1,2,5,6,7,8$ - BLAD free; lane 3 BLAD carrier; lane 4 - GeneRuler 100 bp DNA Ladder (Thermo Scientific) 


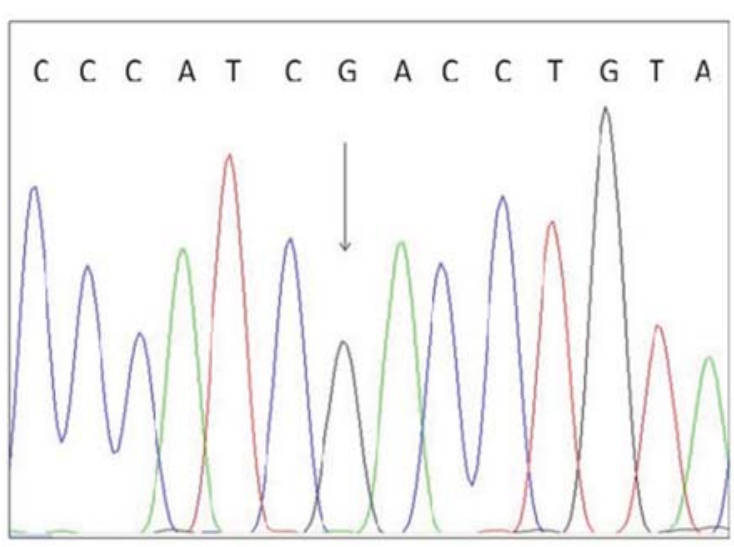

Figure 3. Electropherogram of BLAD free animal. The heterozygous position is indicated by an arrow.

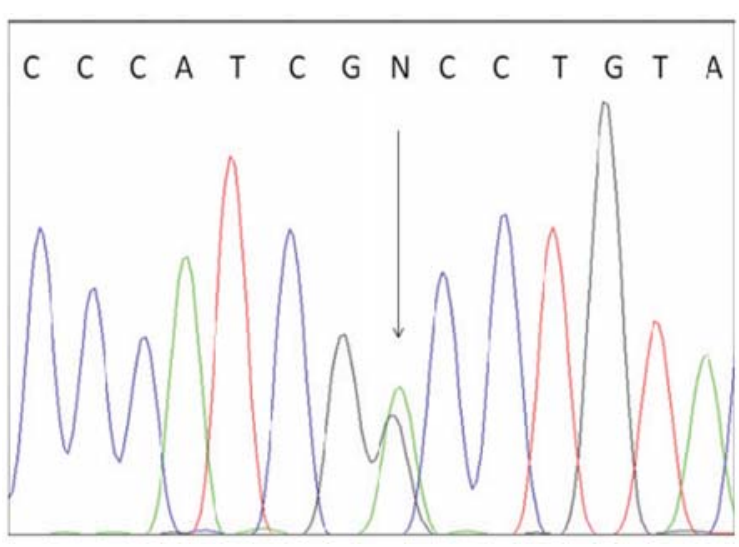

Figure 4. Electropherogram of BLAD carrier. The heterozygous position is indicated by an arrow.
To confirm the correctness of these results we performed direct sequencing of one BLAD-free and two BLAD-carrier PCR products. The results are shown in Fig. 3 and Fig. 4.

CVM carriers were detected by PCR-PIRA followed by digestion with PstI restriction endonuclease and confirmed by direct sequencing of the heterozygous region. The amplification product size obtained with CVM-PIRA-F and CVM-PIRA-R primers is shown in Fig. 5. The restriction pattern for discriminating between non-carrier and heterozygous carrier animals is shown in Fig. 6.

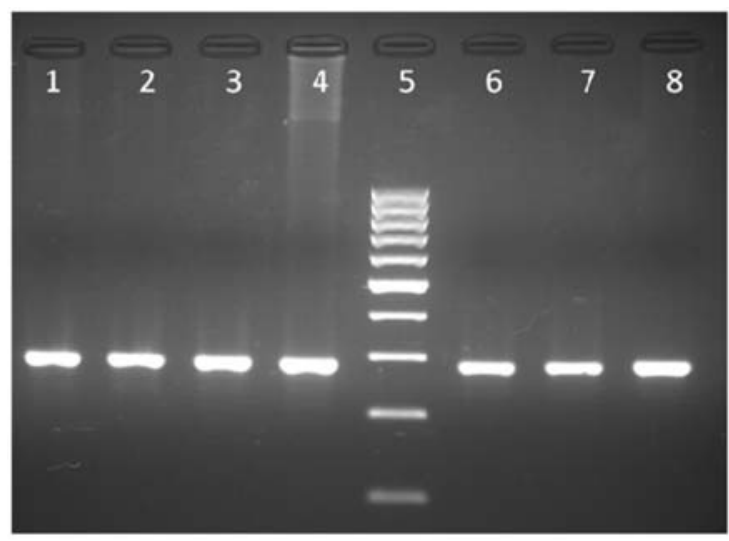

Figure 5. Lanes 1, 2, 3, 4, 6, 7, 8 - PCR product of 287 bp obtained with CVM-PIRA-F and CVM-PIRA-R primers; lane 5 - GeneRuler 100 bp DNA Ladder (Thermo Scientific)

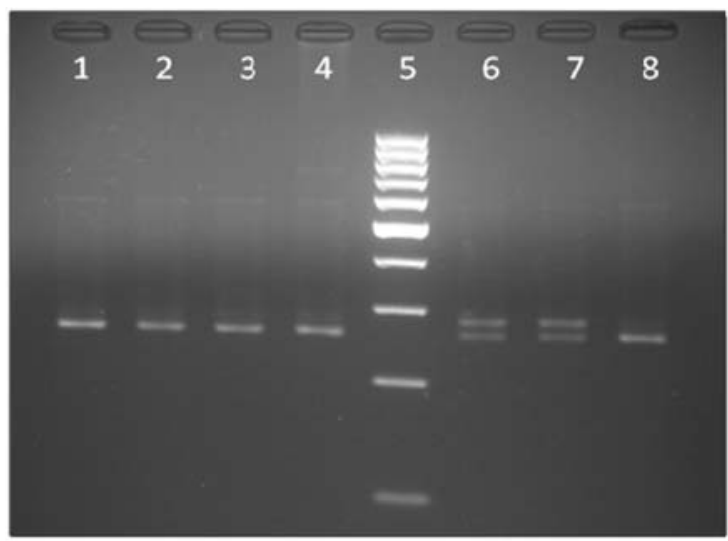

Figure 6. Lanes 1, 2, 3, 4, 8-CVM free; lanes 6 and 7 - CVM carriers; lane 5 - GeneRuler 100 bp DNA Ladder (Thermo Scientific) 
These results were confirmed by direct sequencing of the PCR product with one of the newly designed primers either SLC-F or SLC-R (Table 1). The results of the sequence analysis are shown in Fig. 7 and Fig. 8. although not found in this study, would yield six different fragments of 19, 25, 39, 54, 83 and $121 \mathrm{bp}$. Following this, heterozygous genotypes showed six fragments (19 bp fragment was not visible) of which the 83 bp fragment (arrow) was specific for

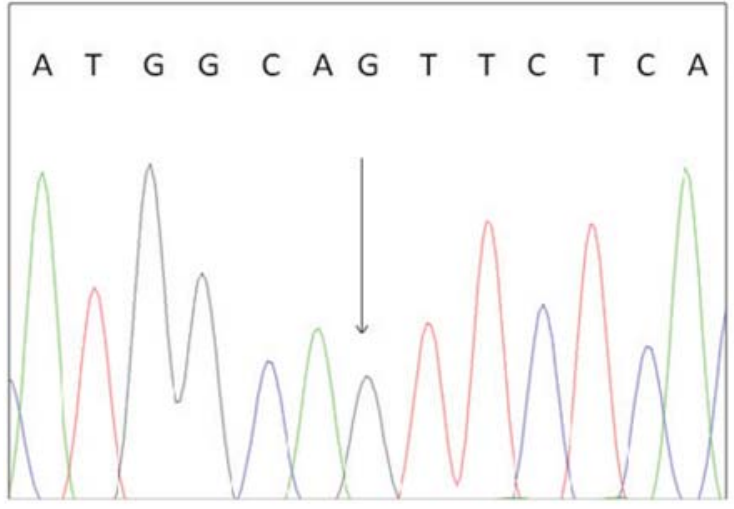

Figure 7. Electropherogram of CVM free animal. The heterozygous position is indicated by an arrow.

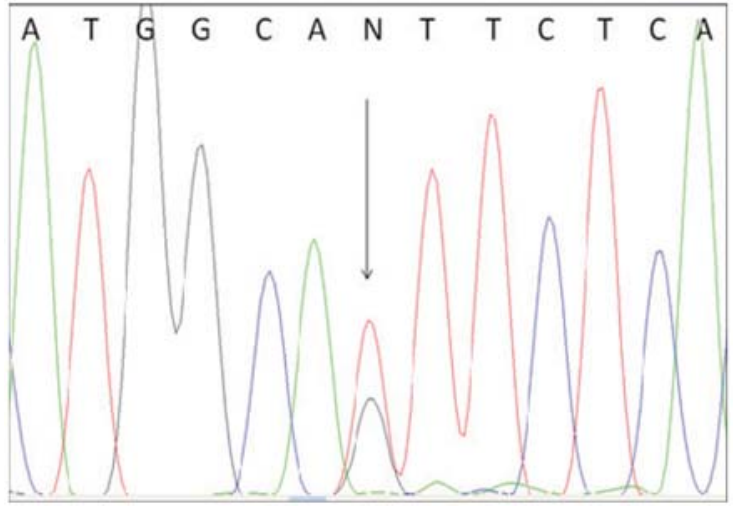

Figure 8. Electropherogram of CVM carrier. Heterozygous position is indicated by an arrow.

\section{DISCUSSION}

PCR followed by RFLP showed to be a reliable method for detection of these two single nucleotide polymorphisms since digestibility by restriction endonucleases strictly depends on the nucleotide sequence of the amplified product. Since TaqI cleaves only the wild type allele while the mutation destroys the recognition site, the restriction pattern of the amplified DNA product of $341 \mathrm{bp}$ for detection of CD18 genotype with this enzyme revealed two fragments of 191 and $150 \mathrm{bp}$ when non-carrier DNA was cleaved and three fragments of 341, 191 and 150 bp when carrier DNA was cleaved. Affected animals would show only one undigested fragment of $341 \mathrm{bp}$, but were not found in this study. Although our findings revealed slightly different fragment sizes then the ones previously reported with the same primer pair $(5,21,31)$, the restriction pattern for identifying carrier animals after digestion of the amplified product with $T a q \mathrm{I}$ is in accordance with these authors.

Detection of the BLAD carriers with the HaeIII enzyme was done in the following manner: the fragment amplified from a non-carrier animals contained four recognition sites for this enzyme, thus this genotype showed five fragments of 25 , $39,54,102$ and $121 \mathrm{bp}$; since the point mutation creates another recognition site affected animals, this genotype. Thus, the restriction fragment pattern obtained with HaeIII in this study is in accordance with previously published reports $(23,35,41)$ in which this enzyme was used to detect heterozygous BLAD carriers.

To confirm the results of the PCR-RFLP analysis we performed direct sequencing of one BLAD-free and two BLAD-carrier PCR products. The electropherogram of a wild type homozygous animal indicated only nucleotide $A$ at the position 383 of the bovine $\mathrm{CD} 18$ gene, while the carriers of the mutant allele revealed presence of two nucleotides (A and G) at the same position.

CVM carriers were detected by PCR-PIRA (Primer Introduced Restriction Analysis), a method initially described by Kanae et al. (19) and confirmed by direct sequencing of the heterozygous region. Since the G559T mutation of the SLC35A3 gene neither creates nor destroys recognition site for any restriction enzyme, the forward primer is designed to have two mismatched nucleotides in order to create, in the wild-type allele, a recognition sequence for the Pst $\mathrm{I}$ enzyme while the mutant allele remains undigested. But unlike Kanae et al.(19) who reported amplification product of $233 \mathrm{bp}$, our results showed a longer PCR product which, after comparing with the sequence submitted by Thomsen et al. (44) with GenBank Accession Number AY160683, we calculated to be 287 bp long. Since 
the mismatched forward primer creates a recognition site for PstI only in the wild-type allele, non-carriers yielded two fragments of 264 and 23 bp of which the latter was not visible on $2.5 \%$ agarose gel and heterozygous carriers showed two fragments of 287 and 264 bp (Fig. 6). Affected animals would show one fragment of $287 \mathrm{bp}$, but were not found in this study.

The electropherogram of the non-carriers showed only nucleotide $G$ at the position 559 of the SLC35A3 gene, while heterozygous carriers revealed presence of two nucleotides ( $\mathrm{G}$ and $\mathrm{T})$ at the same position.

\section{CONCLUSION}

The detection method based on PCR - RFLP analysis is a powerful tool for identification of both BLAD and CVM carriers. The primers that we used for identification of the BLAD genotype successfully amplify a region of $341 \mathrm{bp}$ and digestion with either TaqI or HaeIII enzymes makes possible easily to distinguish DNA samples of non-carriers from heterozygote carrier animals. Detection of CVM carriers can easily be accomplished with PCR-PIRA amplification with mismatched forward primer followed by RFLP analysis with Pst I endonuclease.

This is the first published report on existence of BLAD and CVM carriers in the HF cattle population in Republic of Macedonia. Although they were found at low frequency, this study demonstrates a need for further examination of more animals in this population in order to determine more accurately the extent of dispersion of these deleterious alleles, but also it emphases the need for obligatory testing of each candidate bull before entering the A.I. program to prevent their accidental spread to a large number of offspring.

\section{REFERENCES}

1. Agerholm J.S., C. Bendixen, J. Arnbjerg, O. Andersen, O (2004). Morphological variation of "complex vertebral malformation" in Holstein calves. J. Vet. Diagn. Invest. 16: 548-553.

2. Agerholm J.S., C. Bendixen, O. Andersen, J. Arnbjerg (2001). Complex vertebral malformation in Holstein calves. J. Vet. Diagn. Invest. 13: 283-289.
3. Agerholm J.S., H. Houe, C.B. Jorgensen et al. (1993). Bovine leukocyte adhesion deficiency in Danish Holstein-Friesian cattle. Patho-anatomical description of affected calves. Acta Vet. Scand. 34: 237-243.

4. Akyuz B. O. Ertugrul (2006). Detection of bovine leukocyte adhesion deficiency (BLAD) in Turkish native and Holstein cattle. Acta Vet. Hung. 54 (2): 173-178.

5. Akyuz B., O. Ertugrul, O. Korkmaz Agaoglu (2010). Detection of bovine leukocyte adhesion deficiency (BLAD) allele in Holstein cows reared in Kayseri Vicinity. Kafkas Univ. Vet. Fak. Derg. 16 (2): 519-521.

6. Andrews A.H., J. Fishwick, R.J. Waters (1996). Bovine leucocyte adhesion deficiency (BLAD) in a one year old Holstein-Friesian bull - the first report in the United Kingdom. Brit. Vet. J. 152: 347-351.

7. Bendixen C., S. Svendsen, H. Jensen et al. (2002). Genetic test for the identification of carriers of complex vertebral malformations in cattle. Publication No. PCT/WO 02/40709 A2 United States Patent: World Intelectual Property Organization: 7094544.

8. Bernadina W.E., A.J. Duits, H.C. Kalsbeek et al. (1993). Leukocyte adhesion deficiency in a Dutch Holstein calf -a case with a clear cut family history. Vet. Immunol. Immunopathol. 37: 295-308.

9. Betka L., T. Kavar, V. Meglic (2008). Detection of recessive mutations (CVM, BLAD and RED FACTOR) in Holstein bulls in Slovenia. Journal of Central European Agriculture 9 (1): 101-106.

10. Chu Q., D. Sun, Y. Yu et al. (2008). Identification of complex vertebral malformation carriers in Chinese Holstein. J. Vet. Diagn. Invest. 20: 228-230.

11. Duncan R.B., C.B. Carrig, J.S. Agerholm, C. Bendixen (2001). Complex vertebral malformation in Holstein calf: Report of a case in the USA. J. Vet. Diagn. Invest. 13: 333-336.

12. Esmaelizad M. N. Asadzadeh, Molasalehi M. et al. (2002). Molecular characterization of CD18 gene and identification of BLAD carrier bulls in Iran. Proc. $7^{\text {th }}$ World Congr. Genetics Applied to Livestock Production, Montepellier, France.

13. Gerardi A.S. (1996). Bovine leukocyte adhesion deficiency: a brief overview of a modern disease and its implication. Folia Vet. 40: 65-69.

14. Ghanem M.E., M. Akita, T. Suzuki (2008). Complex vertebral malformation in Holstein cows in Japan and its inheritance to crossbred F1 generation. Anim. Reprod. Sci. 103: 348-354.

15. Gourreau J.M., L.V. Massen, R. Braque (1998). Cas clinique. Toris cas cliniques de BLAD. Point Vet. 29: 357-358. 
16. Huang Y.C., D.Y. Lin, C.Y. Tseng et al. (2001). Comparison of milk production and quality of BLAD-carrier and normal Holstein-Friesian cows in Taiwan. J. Taiwan Livestock Res. 34: 271-278.

17. Huang Y.C., H.L. Chang, D.Y. Lin et al. (2000). Gene frequencies of bovine leukocyte adhesion deficiency of Holstein in Taiwan. J. Taiwan Livestock Res. 33: $37-47$.

18. Jorgensen C.B., J.S. Agerholm, J. Pedersen, P.D. Thomsen (1993). Bovine leukocyte adhesion deficiency in Danish Holstein-Friesian cattle. PCR screening and allele frequency estimation. Acta Vet. Scand. 34: 231-236.

19. Kanae Y., D. Endoh, H. Nagahata, M. Hayashi (2005). A method for detecting complex vertebral malformation in Holstein calves using polymerase chain reaction-primer introduced restriction analysis. J. Vet. Diagn. Invest. 17: 258-262.

20. Kehrli M.E., C. Schmalstieg, D.C. Anderson, M.J. Van Der Maaten, B.J. Hughes, M.R. Akermann, C.L. Wilhemsen, G.B. Brown, M.G. Stevens, C.A. Whetstone (1990). Molecular definition of the bovine granulocytopathy syndrome: Identification of deficiency of the Mac-1 (CD11b/CD18) glycoprotein. Am. J. Vet. Res. 51: 1826-1836.

21. Kriegesmann B., S. Jansen, B.G. Baumgartner, B. Brening (1997). Partial genomic structure of the bovine CD18 gene and the refinement of test for Bovine Leukocyte Adhesion Deficiency. J. Dairy Sci. 80: 2547-2549.

22. Lee Y.K., K.M. Chang, I.S. Nam et al. (2002). Studies on the detection of congenital genetic disorder in Holstein proven and candidate bulls. J. Anim. Sci. Tech. 44: 279-288.

23. Logar B., T. Kavar, V. Meglic (2008). Detection of recessive mutations (CVM, BLAD and Red Factor) in Holstein bulls in Slovenia. Journal of Central European Agriculture vol. 9 (1): 101-106.

24. Meydan H., M.A. Yildiz, J.S. Agerholm (2010). Screening for bovine leukocyte adhesion deficiency, deficiency of uridine monophosphate synthase, complex vertebral malformation, bovine citrullinaemia and factor XI deficiency in Holstein cows reared in Turkey. Acta Vet. Scand. 52: 56-63.

25. Meylan M., R. Abegg, H. Sager et al. (1997). Fallvorstellung: Bovine leukozyten Adhasions Defizienz (BLAD) in der Schweiz. Schweiz. Arch. Tierheilk. 139: 277-281.

26. Nagahata H., H. Oota, A. Nitanai et al. (2002). Complex vertebral malformation in a stillborn Holstein calf in Japan. J. Vet. Med. Sci. 64: 11071112.
27. Nagahata H., T. Miura, K. Tagakaki et al. (1997). Prevalence and allele frequency estimation of bovine leukocyte adhesion deficiency (BLAD) in Holstein-Friesian cattle in Japan. J. Vet. Med. Sci. 59: 233-238.

28. Natonek M. (2000). Identification of BLAD mutation in cattle with PCR-RFLP method. Biul. Inf. Inst. Zootech. 38: 29-33.

29. Nielsen J.S., C.B. Jorgensen and P.D. Thomsen (1992). Bovine leukocyte adhesion syndrome. A new hereditary disease in the Danish Holstein Friesian breed. Dan. Veterinaertidsskr. 75: 276-277.

30. Nielsen U.S., G.P. Aamand, O. Andersen, et al. (2003): Effects of complex vertebral malformation on fertility traits in Holstein cattle. Livest. Prod. Sci. 79: 233-238.

31. Oner Y., A. Keskin, C. Elmaci (2010). Identification of BLAD, DUMPS, Citrullinaemia and Factor XI deficiency in Holstein cattle in Turkey. Asian J. Anim. Vet. Adv., 2010

32. Padeeri M., K. Vijaykumar, S. Grupe et al. (1999). Incidence of hereditary citrullinemia and bovine leucocyte adhesion deficiency syndrome in Indian dairy cattle (Bos taurus, Bos indicus) and buffalo (Bubalus bubalis) population. Arch. Tierz. 42: 347-352.

33. Patel R.K., K.M. Singh, K.J. Soni et al. (2007). Low incidence of bovine leukocyte adhesion deficiency (BLAD) carriers in Indian cattle and buffalo breeds. J. Appl. Genet. 48: 153-155.

34. Revell S. (2001). Complex vertebral malformation in a Holstein calf in the UK. Vet. Rec. 149: 659-660.

35. Ribeiro L.A., E.E. Baron, M.L. Martinez et al. (2000). PCR screening and allele frequency estimation of bovine leukocyte adhesion deficiency in Holstein and Gir cattle in Brazil. Genet. Mol. Biol. 23: 831-834.

36. Rusc A., S. Kaminski (2007). Prevalence of complex vertebral malformation carriers among Polish Holstein-Friesianbulls.J.Appl.Genet.48(3):247-252.

37. Rutten V.P.M.G., A. Hoek, K.E. Muller (1996). Identification of monoclonal antibodies with specificity to $\alpha$ - or $\beta$ - chains of $\beta 2$-integrins using peripheral blood leukocytes of normal and Bovine Leukocyte Adhesion Deficient (BLAD) cattle. Vet. Immun. Immunopathol. 52: 341-345.

38. Schilcher F., H. Hotter, I. Tammen et al. (1995). Occurrence of bovine leukocyte adhesion deficiency (BLAD) of Holstein Friesian in Austria. Wiener Tierarztliche Monatsschrift. 82: 207-212, in German.

39. Shuster D.E., B.T. Bosworth, M.E. Kehrli Jr. (1992). Sequence of the bovine CD18-encoding cDNA: comparison with the human and murine glycoproteins. Gene 114 (2): 267-271. 
40. Shuster D.E., M.E. Kehrli Jr., M.R. Ackerman, R.O. Gilbert (1992). Identification and prevalence of a genetic defect that causes leukocyte adhesion deficiency in Holstein cattle. Proc. Natl. Acad. Sci. 89: 9225-9229.

41. Snoj T. , G. Majdic (2003). Bovine leukocyte adhesion deficiency (BLAD) in Slovenian population of Holstein-Friesian bulls. Vet. Novice 29: 445-448.

42. Stober M., A. Kuczka, J. Pohlenz (1991). Bovine leukocyte adhesion deficiency (BLAD=HagemoserTakahashi syndrome) - clinical, pathoanatomical and pathohistological findings. Deutsch Tierarztliche Wochenschrift 98: 443.

43. Tammen I., H. Klippert, A. Kuczka et al. (1996). An improved DNA test for bovine leukocyte adhesion deficiency. Res. Vet. Sci. 60: 218-221.
44. Thomsen B., P. Horn, F. Panitz et al. (2006). A missense mutation in the bovine SLC35A3 gene, encoding a UDP-N-acetylglucosamine transporter, causes complex vertebral malformation. Genome Res. 16: 97-105

45. Wang C., Q. Tong, X.Z. Hu et al. (2011). Identification of complex vertebral malformation carriers in Holstein cattle in south China. Genet. Mol. Res. 10(4): 2443-2448.

46. Wouda W., I.J. Visser, G.H. Borst et al. (2000). Developmental anomalies in aborted and stillborn calves in The Netherlands. Vet. Rec. 147: 612

47. Zhang et al. (2012): A novel method for rapid and reliable detection of complex vertebral malformation and bovine leukocyte adhesion deficiency in Holstein cattle. Journal of Animal Science and Biotechnology 2012, 3:24. 